\title{
Identification of core differentially methylated genes in glioma
}

\author{
JING XUE ${ }^{1-3^{*}}$, HAI-XIA GAO ${ }^{1,2^{*}}$, WEI SANG ${ }^{1 *}$, WEN-LI CUI ${ }^{1}$, MING LIU $^{1}$, \\ YAN ZHAO $^{1}$, MENG-BO WANG ${ }^{1,2}$, QIAN WANG ${ }^{1}$ and WEI ZHANG ${ }^{1}$ \\ ${ }^{1}$ Department of Pathology, The First Affiliated Hospital of Xinjiang Medical University, Urumqi, Xinjiang 830054; \\ ${ }^{2}$ Department of Pathology, Xinjiang Medical University, Urumqi, Xinjiang 830011; ${ }^{3}$ Department of Pathology, \\ The Fourth Affiliated Hospital of Xinjiang Medical University, Urumqi, Xinjiang 830000, P.R. China
}

Received April 3, 2019; Accepted August 20, 2019

\section{DOI: $10.3892 / 01.2019 .10955$}

\begin{abstract}
Differentially methylated genes (DMGs) serve a crucial role in the pathogenesis of glioma via the regulation of the cell cycle, proliferation, apoptosis, migration, infiltration, DNA repair and signaling pathways. This study aimed to identify aberrant DMGs and pathways by comprehensive bioinformatics analysis. The gene expression profile of GSE28094 was downloaded from the Gene Expression Omnibus (GEO) database, and the GEO2R online tool was used to find DMGs. Gene Ontology (GO) functional analysis and Kyoto Encyclopedia of Genes and Genomes pathway enrichment analysis of the DMGs were performed by using the Database for Annotation Visualization and Integrated Discovery. A protein-protein interaction (PPI) network was constructed with Search Tool for the Retrieval of Interacting Genes. Analysis of modules in the PPI networks was performed by Molecular Complex Detection in Cytoscape software, and four modules were performed. The hub genes with a high degree of connectivity were verified by The Cancer Genome Atlas database. A total of 349 DMGs, including 167 hypermethylation genes, were enriched in biological processes of negative and positive regulation of cell proliferation and positive regulation of transcription from RNA polymerase II promoter. Pathway analysis enrichment revealed that cancer regulated the pluripotency of stem cells and the PI3K-AKT signaling pathway, whereas 182 hypomethylated genes were enriched in biological processes of immune response, cellular response to lipopolysaccharide and peptidyl-tyrosine phosphorylation. Pathway enrichment analysis revealed cytokine-cytokine receptor interaction, type I diabetes mellitus and TNF signaling pathway. A total of 20 hub genes were identified, of which eight genes were associated with survival, including notch receptor 1 ( $\mathrm{NOTCHI}$,
\end{abstract}

Correspondence to: Professor Wei Zhang, Department of Pathology, The First Affiliated Hospital of Xinjiang Medical University, 137 Liyushan Southern Road, Urumqi, Xinjiang 830054, P.R. China

E-mail: zwyhr100@163.com

${ }^{*}$ Contributed equally

Key words: glioma, bioinformatics, methylation, biomarker
SRC proto-oncogene (also known as non-receptor tyrosine kinase, $S R C$ ), interleukin 6 (IL6), matrix metallopeptidase 9 (MMP9), interleukin 10 (IL10), caspase 3 (CASP3), erb-b2 receptor tyrosine kinase 2 (ERBB2) and epidermal growth factor $(E G F)$. Therefore, bioinformatics analysis identified a series of core DMGs and pathways in glioma. The results of the present study may facilitate the assessment of the tumorigenicity and progression of glioma. Furthermore, the significant DMGs may provide potential methylation-based biomarkers for the precise diagnosis and targeted treatment of glioma.

\section{Introduction}

Glioma is a type of primary central nervous system (CNS) solid tumor that arises from glial cells and is aggressive and lethal (1). It comprises $\sim 30 \%$ of all CNS tumors and $80 \%$ of all malignant brain tumors (2). According to the 2016 World Health Organization (WHO) guidelines, gliomas can be classified into grades I-IV depending on 'integrated diagnosis', combining histopathological and molecular features (3). The most malignant type is grade IV glioblastoma (GBM), the overall survival (OS) time of which is only 14 months (4). Lower grade glioma (LGG; grades II and III) exhibits benign tendencies and leads to a favorable prognosis for patients (5). However, it has a high rate of recurrence and increases in grade over time (6). Currently, the common treatment strategies for the treatment of glioma involve surgical resection, after which adjuvant chemotherapy and/or radiotherapy are used; however, the clinical outcomes of glioma remain unsatisfactory. The pathogenesis of glioma involves multiple factors and steps, comprising genetic and epigenetic alterations. Despite a number of mechanisms of oncogenesis have been verified in glioma, including retinoblastoma, $\mathrm{p} 53$ and receptor tyrosine kinase signaling pathways, the genetic factors and precise mechanism of human glioma remain poorly understood (7). Therefore, vital molecular biomarkers and oncogenic pathways associated with accurate diagnosis and patient survival in glioma require further identification.

Aberrant $\mathrm{CpG}$ island methylation is a primary epigenetic modified form of DNA sequence in malignancy (8). The functions of key genes can be altered through methylation to modify their expression, including hypermethylation of tumor suppressor genes (TSGs) and hypomethylation of oncogenes $(9,10)$. The methylation status of multiple TSGs may 
serve as a biomarker for the early diagnosis and prediction of prognosis (11). For example, promoter methylation-induced silencing of the O6-methylguanine-DNA methyltransferase DNA-repair gene has been demonstrated to be a powerful predictor of the sensitivity of alkylating chemotherapy in patients with glioma with long survival rates (12). The methylation level of death associated protein kinase 1 is associated with clinical features and outcomes of glioma; hypermethylation at site-1,527 or together with site-1,543 indicates good sensitivity to postoperative therapies, particularly radiotherapy (13). A number of TSGs associated with cell cycle, proliferation and DNA repair have been identified in glioma, including cyclin dependent kinase inhibitor $2 \mathrm{~A}(C D K N 2 \mathrm{~A}$, also known as $\left.P 16^{\mathrm{INK} 4 \mathrm{a}}, P 14^{\mathrm{ARF}}\right)$, TNF receptor superfamily member 11a (TNFRSF11A) and nuclear receptor binding SET domain protein 1 (NSDl) (14-17). Therefore, identifying differentially methylated genes (DMGs) by comparing the differences in DNA methylation status of glioma with that of normal brain tissue is crucial for elucidating the development, progression and metastasis of glioma and may be used as a guide for targeting drugs for glioma.

At present, microarray analysis based on high-throughput platforms is an efficient tool that has been applied to screen virtual genetic or epigenetic alterations in carcinogenesis, and to identify biomarkers for the diagnosis and prognosis of cancer (18). In the present study, DMGs were examined in glioma by online bioinformatics resources. The expression profile of GSE28094 from the Gene Expression Omnibus (GEO) database was downloaded to identify the DMGs between glioma and normal brain tissue. Subsequently, hierarchical clustering and functional enrichment analyses of the Gene Ontology (GO) and Kyoto Encyclopedia of Genes and Genomes (KEGG) pathways by Database for Annotation Visualization and Integrated Discovery (DAVID) for the DMGs were performed. A protein-protein interaction (PPI) network of DMGs was constructed and the main hub genes with high degree of connectivity were examined by Search Tool for the Retrieval of Interacting Genes (STRING), and the results were further validated by The Cancer Genome Atlas (TCGA) data to identify DMGs in the expression of glioma. This study provided comprehensive biological information for DMGs and novel targets for the diagnosis and accurate treatment of glioma.

\section{Materials and methods}

Microarray data. To identify DMGs between glioma and normal brain tissue, the GSE28094 gene expression microarray, contributed by Fernandez et al (19), was downloaded from the GEO database (https://www.ncbi.nlm.nih.gov/gds/) of the National Center for Biotechnology Information, a public functional genomics data repository. GSE28094 was based on the GPL9183 platform (Illumina GoldenGate Methylation Cancer Panel I). For the present study, 90 gliomas and 6 normal brain tissues were collected from GSE28094.

Data processing of DMGs. GEO2R (https://www.ncbi.nlm. nih.gov/geo/geo2r/) online software was used to analyze GSE28094 and detect DMGs between gliomas and normal brain tissues. GEO2R is an interactive online tool in which $\geq 2$ groups of samples can be compared in a GEO series to display differentially expressed genes under specific experimental conditions (20). The adjusted P-values were used to decrease the false positive rate using the Benjamini and Hochberg false discovery rate method. Adjusted $\mathrm{P}<0.05$ and $|t|>2$ were used as the cut-off values for detecting DMGs. Finally, 349 DMGs were obtained, including 167 upregulated and 182 downregulated genes.

GO and KEGG pathway analyses of DMGs. GO analysis served as a crucial tool to annotate genes and gene products and to identify characteristic biological functions using high-throughput genome or transcriptome data (21), including biological process (BP), cellular component (CC) and molecular function (MF). KEGG is a collection of databases that can help to annotate genomes, biological pathways, diseases, chemical substances and drugs (22). DAVID (version 6.8; https://david.ncifcrf.gov/) was used to perform KEGG pathway enrichment analysis for the selected DMGs. $\mathrm{P}<0.05$ was considered to indicate a statistically significant difference.

PPI network and module analysis. PPI analysis was performed to illustrate the interactions and functions of the selected DMGs via STRING (version 11.0; http://string-db.org). Cytoscape is a vital workflow component for executing network visualization, analysis and publishing tasks (23). To illustrate the potential interactions among those DMGs, STRING in Cytoscape (version 3.6.0) was applied and the DMGs were mapped into STRING. A confidence score $\geq 0.4$ and a maximum number of interactors $=0$ were set as the cut-off criterion. Molecular complex detection (MCODE, version 1.5.1) is a method to analyze densely connected regions in PPI networks (24). This method was used to screen modules of the PPI network in Cytoscape with a degree cut-off $=2$, node score cut-off $=0.2$, $\mathrm{k}$-core $=2$ and maximum depth $=100$. The pathway analysis of genes in these modules was also performed by DAVID. In addition, the top 20 hub genes with a high degree of connectivity were inserted into STRING with a confidence score of $\geq 0.4$ and a maximum number of interactors $=0$. GO and KEGG pathway analyses were also used to examine the potential interactions.

TCGA data validation of the hub DMGs. In view of the small sample size of this study, further validation analysis was performed to verify the results of TCGA data. GEPIA (http://gepia.cancer-pku.cn/index.html) is a publicly available interactive web server that can analyze the RNA sequencing expression data of 9,736 tumors and 8,587 normal samples from TCGA and GTEx projects by a standard processing pipeline (25). It supports customizable functions, including tumor and normal tissue differential expression analyses, and information can be obtained on the expression level of hub DMGs in glioma and normal brain tissue. Boxplots were displayed to visualize the association. By acquiring pathologically confirmed immunohistochemical data of glioma and normal brain tissue based on the Human Protein Atlas (HPA; https://www.proteinatlas.org/), the expression of these hub DMGs was further validated. Hub DMGs in glioma were identified using HPA. From the extensive sample collection of antibodies against the DMGs, the sample with the strongest 
Table I. GO analysis of differentially methylated genes associated with glioma.

A, Hypermethylation

\begin{tabular}{|c|c|c|c|c|}
\hline GO analysis & Term & Count & $\%$ & P-value \\
\hline GOTERM_BP_DIRECT & GO:0008285 negative regulation of cell proliferation & 23 & 14.7436 & $1.43 \times 10^{-11}$ \\
\hline GOTERM_BP_DIRECT & GO:0008284 positive regulation of cell proliferation & 24 & 15.3846 & $5.14 \times 10^{-11}$ \\
\hline GOTERM_BP_DIRECT & $\begin{array}{l}\text { GO:0045944 positive regulation of transcription from RNA } \\
\text { polymerase II promoter }\end{array}$ & 34 & 21.7949 & $6.75 \times 10^{-11}$ \\
\hline GOTERM_BP_DIRECT & GO:0046777 protein autophosphorylation & 15 & 9.6154 & $6.80 \times 10^{-10}$ \\
\hline GOTERM_BP_DIRECT & GO:0042981 regulation of apoptotic process & 16 & 10.2564 & $1.23 \times 10^{-9}$ \\
\hline GOTERM_CC_DIRECT & GO:0005737 cytoplasm & 79 & 50.6410 & $6.58 \times 10^{-9}$ \\
\hline GOTERM_CC_DIRECT & GO:0005886 plasma membrane & 61 & 39.1026 & $3.46 \times 10^{-6}$ \\
\hline GOTERM_CC_DIRECT & GO:0005654 nucleoplasm & 45 & 28.8462 & $1.77 \times 10^{-5}$ \\
\hline GOTERM_CC_DIRECT & GO:0048471 perinuclear region of cytoplasm & 18 & 11.5385 & $2.05 \times 10^{-5}$ \\
\hline GOTERM_CC_DIRECT & GO:0005576 extracellular region & 30 & 19.2308 & $7.41 \times 10^{-5}$ \\
\hline GOTERM_MF_DIRECT & GO:0005515 protein binding & 121 & 77.5641 & $4.77 \times 10^{-12}$ \\
\hline GOTERM_MF_DIRECT & GO:0008134 transcription factor binding & 16 & 10.2564 & $4.30 \times 10^{-8}$ \\
\hline GOTERM_MF_DIRECT & GO:0046982 protein heterodimerization activity & 18 & 11.5385 & $1.01 \times 10^{-6}$ \\
\hline GOTERM_MF_DIRECT & GO:0005102 receptor binding & 15 & 9.6154 & $3.80 \times 10^{-6}$ \\
\hline GOTERM_MF_DIRECT & GO:0005524 ATP binding & 32 & 20.5128 & $8.54 \times 10^{-6}$ \\
\hline
\end{tabular}

B, Hypomethylation

\begin{tabular}{|c|c|c|c|c|}
\hline GO analysis & Term & Count & $\%$ & P-value \\
\hline GOTERM_BP_DIRECT & GO:0006955 immune response & 32 & 18.4971 & $1.89 \times 10^{-18}$ \\
\hline GOTERM_BP_DIRECT & GO:0071222 cellular response to lipopolysaccharide & 15 & 8.6705 & $6.78 \times 10^{-12}$ \\
\hline GOTERM_BP_DIRECT & GO:0018108 peptidyl-tyrosine phosphorylation & 16 & 9.2486 & $3.60 \times 10^{-11}$ \\
\hline GOTERM_BP_DIRECT & GO:0006954 inflammatory response & 22 & 12.7168 & $2.12 \times 10^{-10}$ \\
\hline GOTERM_BP_DIRECT & GO:0022617 extracellular matrix disassembly & 10 & 5.7804 & $6.50 \times 10^{-8}$ \\
\hline GOTERM_CC_DIRECT & GO:0005615 extracellular space & 56 & 32.3699 & $3.22 \times 10^{-22}$ \\
\hline GOTERM_CC_DIRECT & GO:0005576 extracellular region & 55 & 31.7919 & $6.24 \times 10^{-18}$ \\
\hline GOTERM_CC_DIRECT & GO:0009986 cell surface & 22 & 12.7168 & $2.62 \times 10^{-8}$ \\
\hline GOTERM_CC_DIRECT & GO:0005887 integral component of plasma membrane & 35 & 20.2312 & $1.66 \times 10^{-7}$ \\
\hline GOTERM_CC_DIRECT & GO:0005886 plasma membrane & 67 & 38.7283 & $6.33 \times 10^{-7}$ \\
\hline GOTERM_MF_DIRECT & GO:0005125 cytokine activity & 20 & 11.5607 & $1.17 \times 10^{-14}$ \\
\hline GOTERM_MF_DIRECT & GO:0004713 protein tyrosine kinase activity & 17 & 9.8266 & $2.94 \times 10^{-13}$ \\
\hline GOTERM_MF_DIRECT & GO:0008083 growth factor activity & 15 & 8.6705 & $8.36 \times 10^{-10}$ \\
\hline GOTERM_MF_DIRECT & $\begin{array}{l}\text { GO:0046934 phosphatidylinositol-4,5-bisphosphate } \\
\text { 3-kinase activity }\end{array}$ & 9 & 5.2023 & $1.74 \times 10^{-7}$ \\
\hline GOTERM_MF_DIRECT & $\begin{array}{l}\text { GO:0004715 non-membrane spanning protein tyrosine } \\
\text { kinase activity }\end{array}$ & 8 & 4.6243 & $3.29 \times 10^{-7}$ \\
\hline
\end{tabular}

GO, Gene Ontology; BP, biological process; CC, cell component; MF, molecular function.

intensity and quantity was selected. The normal brain tissue stained for caspase 3 (CASP3) expression was from a female patient (age, 45 years; patient ID, 1539; staining, not detected; intensity, negative; quantity, negative; location, none), and the glioma tissue was from a male patient (age, 56 years; patient ID, 131; staining, medium; intensity, moderate; quantity, 75-25\%; location, nuclear). The normal brain tissue stained for erb-b2 receptor tyrosine kinase 2 (ERBB2) expression was from a female patient (age, 54 years; patient ID, 2523; staining, not detected; intensity, negative; quantity, negative; location, none), and the glioma tissue was from a male patient (age, 66 years; patient ID, 206; staining, high; intensity, strong; quantity, $>75 \%$; location, cytoplasmic/membranous).

Survival analysis of hub genes. GEPIA was used to further investigate the relapse-free survival and OS time data of the 
Table II. KEGG pathway analysis of differentially methylated genes associated with glioma.

A, Hypermethylation

\begin{tabular}{|c|c|c|c|c|}
\hline KEGG analysis & Term & Count & $\%$ & P-value \\
\hline KEGG_PATHWAY & hsa05200:Pathways in cancer & 35 & 22.4 & $1.73 \times 10^{-17}$ \\
\hline KEGG_PATHWAY & hsa04550:Signaling pathways regulating pluripotency of stem cells & 15 & 9.6 & $2.32 \times 10^{-8}$ \\
\hline KEGG_PATHWAY & hsa04151:PI3K-AKT signaling pathway & 21 & 13.5 & $2.17 \times 10^{-7}$ \\
\hline KEGG_PATHWAY & hsa04510:Focal adhesion & 16 & 10.3 & $4.91 \times 10^{-7}$ \\
\hline KEGG_PATHWAY & hsa05218:Melanoma & 10 & 6.4 & $1.17 \times 10^{-6}$ \\
\hline
\end{tabular}

B, Hypomethylation

\begin{tabular}{|c|c|c|c|c|}
\hline KEGG analysis & Term & Count & $\%$ & P-value \\
\hline KEGG_PATHWAY & hsa04060:Cytokine-cytokine receptor interaction & 25 & 14.5 & $1.68 \times 10^{-12}$ \\
\hline KEGG_PATHWAY & hsa04940:Type I diabetes mellitus & 12 & 6.9 & $6.46 \times 10^{-11}$ \\
\hline KEGG_PATHWAY & hsa05332:Graft-vs.-host disease & 11 & 6.4 & $9.97 \times 10^{-11}$ \\
\hline KEGG_PATHWAY & hsa05323:Rheumatoid arthritis & 15 & 8.7 & $1.94 \times 10^{-10}$ \\
\hline KEGG_PATHWAY & hsa04668:TNF signaling pathway & 15 & 8.7 & $2.79 \times 10^{-9}$ \\
\hline
\end{tabular}

KEGG, Kyoto Encyclopedia of Genes and Genomes; hsa, Homo sapiens.

DMGs by Kaplan-Meier survival curves. The hazard ratio (HR) with $95 \%$ confidence intervals and log-rank P-value were calculated and indicated in the plot. Log-rank $\mathrm{P}<0.05$ was considered to indicate a statistically significant difference in the survival curve.

\section{Results}

Identification of DMGs in glioma. After the analysis of GSE28094, a total of 349 DMGs were obtained between glioma and normal brain tissue, including 167 upregulated (hypermethylated) and 182 downregulated (hypomethylated) genes (Table SI).

GO functional enrichment analysis. In order to further understand the underlying mechanism of these DMGs in glioma, all DMGs were imported to the DAVID software. GO function results showed that upregulated DMGs were particularly enriched in BP, including positive and negative regulation of 'cell proliferation', 'positive regulation of transcription from RNA polymerase II promoter', 'protein autophosphorylation' and 'regulation of apoptosis' (Table I). As for CC, the DMGs were enriched in 'cytoplasm', 'plasma membrane', 'nucleoplasm', 'perinuclear region of cytoplasm' and 'extracellular region' (Table I). In addition, MF was enriched predominantly in 'protein binding', 'transcription factor binding', 'protein heterodimerization activity', 'receptor binding' and 'ATP binding' (Table I).

For downregulated DMGs, enriched BP included 'immune response', 'cellular response to lipopolysaccharide', 'peptidyl-tyrosine phosphorylation', 'inflammatory response' and 'extracellular matrix disassembly' (Table I). CC analysis revealed enrichment in 'extracellular space and region', 'cell surface', 'integral component of plasma membrane' and 'plasma membrane' (Table I). In addition, MF showed enrichment in 'cytokine activity', 'protein tyrosine kinase activity', 'growth factor activity', 'phosphatidylinositol-4,5-bisphosphate 3-kinase activity' and 'non-membrane spanning protein tyrosine kinase activity' (Table I). This information suggested that DMGs may serve a crucial function in the tumor immune microenvironment in glioma.

Pathway functional enrichment analysis. KEGG pathway enrichment analysis identified that upregulated DMGs were significantly enriched in pathways in 'cancer', 'signaling pathways regulating pluripotency of stem cells', 'PI3K-AKT signaling pathway', 'focal adhesion' and 'melanoma'. However, downregulated DMGs exhibited enrichment in the pathways of 'cytokine-cytokine receptor interaction', 'type I diabetes mellitus', 'graft-vs.-host disease', 'rheumatoid arthritis' and 'TNF signaling pathway'. These screened pathways suggested that DMGs may have a vital function in the etiology and pathogenesis of glioma (Table II).

PPI network construction and module analysis. Based on the information in the STRING protein query and the data downloaded from public databases, a PPI DMG network was constructed with 349 nodes and 3,796 edges (Fig. 1). To examine the significant modules in this PPI network, MCODE in Cytoscape was performed. Interactions with a score of $>0.9$ were considered significant. The top four modules with the highest scores in the network were selected (Table III). The four modules were mapped into STRING (Fig. 2), and these four core modules were mainly associated with 'cytokine-cytokine receptor interaction', 'proteoglycans in cancer', 'basal cell carcinoma', 'Jak-STAT signaling pathway' and 'cancer pathway' by KEGG pathway enrichment analysis (Table IV). 
Table III. Modules of the protein-protein interaction networks.

\begin{tabular}{|c|c|c|c|c|}
\hline Category & Score & Nodes & Edges & Genes \\
\hline 1 & 27.056 & 37 & 487 & 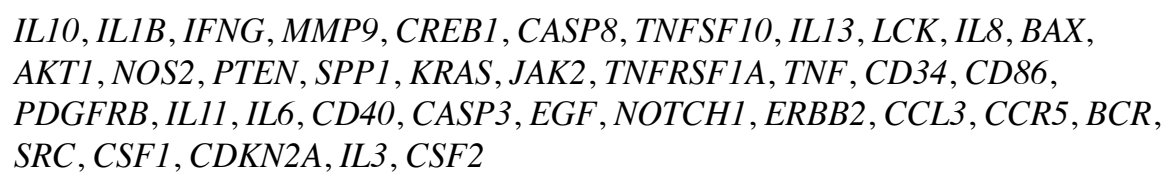 \\
\hline 2 & 8 & 28 & 108 & $\begin{array}{l}\text { TNC, CSF3, ITGB1,IL1A, CD2, FAS, OSM, MPO, TNFRSF10A, PLG, MMP7, } \\
\text { STAT5A, THY1, CD36, IGF1R, CTLA4, SERPINE1, SPI1, PLAU, LIF, MMP14, } \\
\text { IL16, NGF ,IL12B, MMP3, PI3, MMP2, TIMP2 }\end{array}$ \\
\hline 3 & 4 & 6 & 10 & SMO , PTCH1, GLI2, WNT5A, PTHLH, FGF9 \\
\hline 4 & 4 & 4 & 6 & HLA-DQA2, HLA-DPA1, HLA-DPB1, HLA-DOB \\
\hline
\end{tabular}

Score defined as the product of the complex subgraph, density and the number of vertices in the complex subgraph (24).

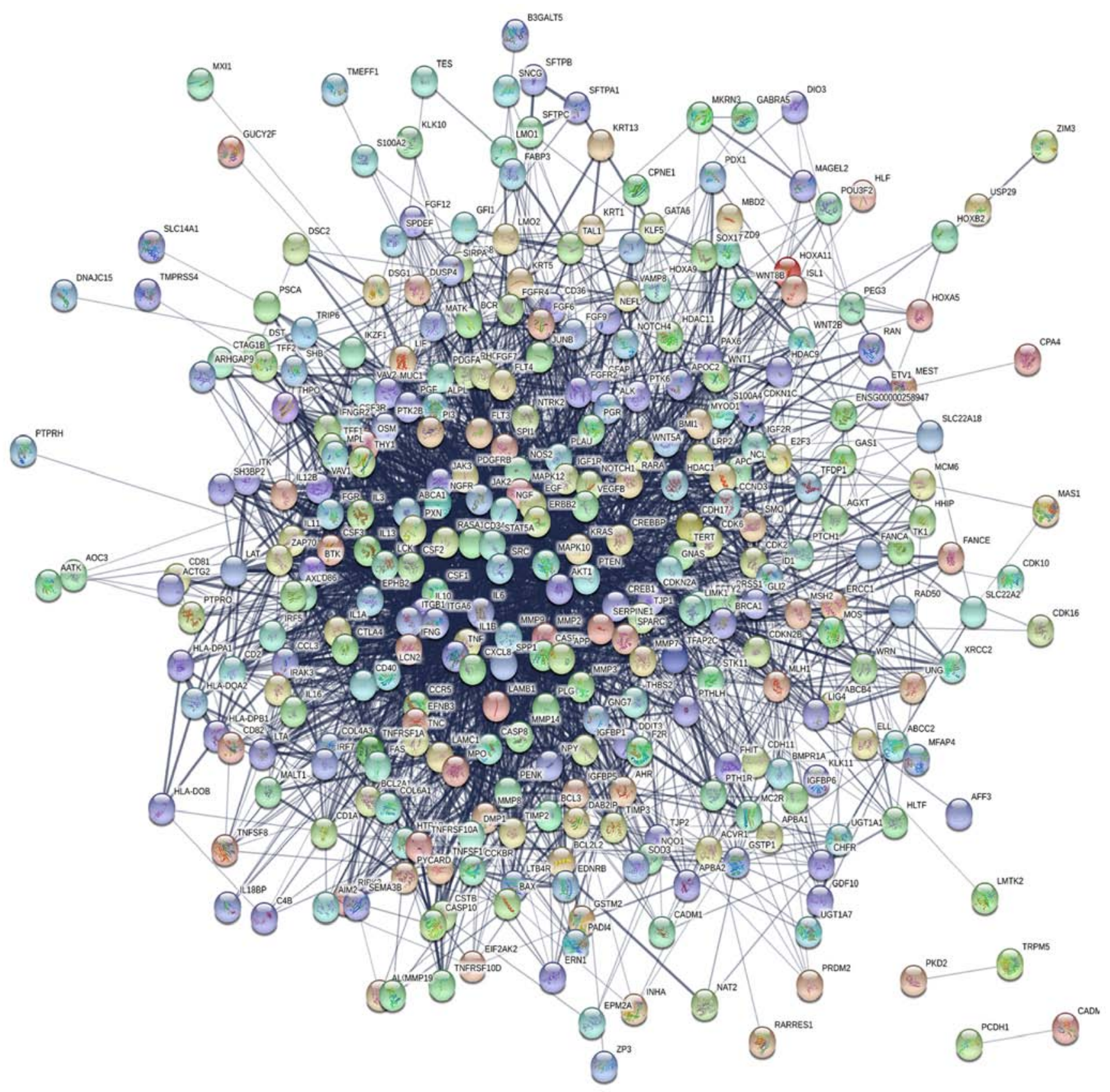

Figure 1. The PPI network of differentially methylated genes. 

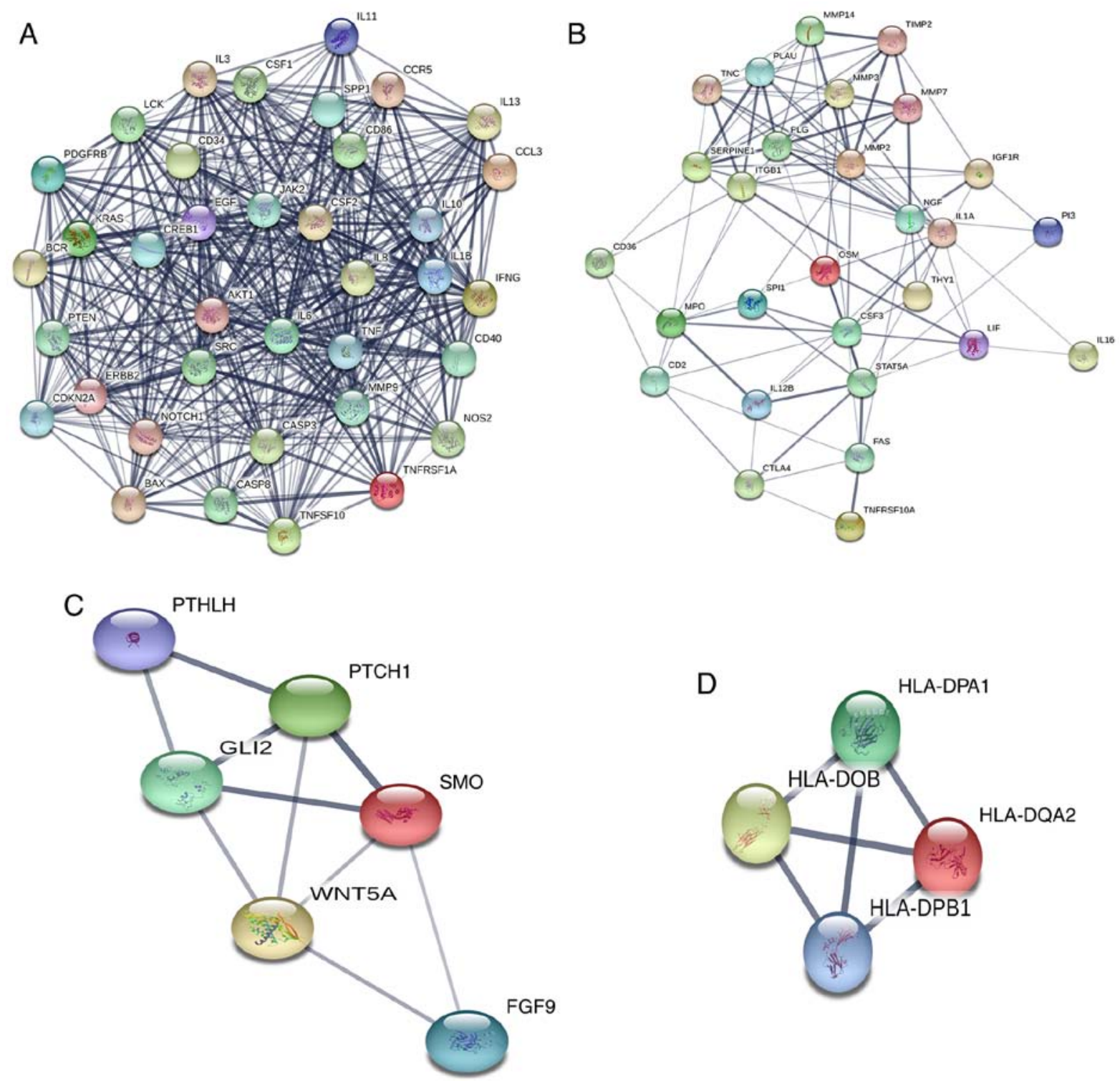

Figure 2. Top four modules for differentially methylated genes were selected. (A) Module 1. (B) Module 2. (C) Module 3. (D) Module 4.

Validation of the hub genes in TCGA database. The top 20 DMGs with the highest degree of connectivity were selected as hub genes in the PPI network. The top 20 hub genes were annotated as AKT serine/threonine kinase 1 (AKTl), SRC proto-oncogene (also known as non-receptor tyrosine kinase; $S R C)$, epidermal growth factor $(E G F)$, tumor necrosis factor (TNF), IL6, NOTCHI, interleukin 8 (IL8), MMP9, IL10, $C A S P 3$, interleukin $1 \beta(I L 1 B)$, colony stimulating factor 2 (CSF2), phosphatase and tensin homolog (PTEN), ERBB2, $C D K N 2 A$, CD34 molecule (CD34), Janus kinase 2 (JAK2), interferon gamma $(I F N G)$, KRAS proto-oncogene $(K R A S)$ and cAMP responsive element binding protein 1 (CREBI). In addition, GEPIA was used to determine the expression levels of hub genes between glioma and normal brain tissue. Compared with that in normal brain tissue, the expression level of the four hub genes, including NOTCH1, CASP, ILIB and CREB1, was significantly elevated both in LGG and GBM (Fig. 3). Boxplots were used to visualize the expression levels of these four hub genes. Furthermore, the immunohistochemical data in glioma and normal brain tissue based on
HPA data showed that the expression of $C A S P 3$ and $E R B B 2$ increased in glioma (Fig. 3). In addition, the expression level of hypomethylated genes increased in GBM compared with that in normal brain tissue, including $I L 6$, notch receptor 1 (NOTCH1), matrix metallopeptidase 9 (MMP9), IL10, IL1B and $C R E B 1$ (Table V). For the aforementioned hub genes, the significant consistency of methylation and expression status partially confirmed the reliability and stability of the results.

Kaplan-Meier plots and expression level of hub DMGs. The prognostic data of the 20 hub DMGs were obtained from GEPIA. The results indicated that overexpression of MMP9 (HR, 3.6; $\mathrm{P}<0.001), E G F\left(\mathrm{HR}, 2.0 ; \mathrm{P}=6.1 \times 10^{-8}\right)$, CASP3 (HR, 4.3; $\mathrm{P}<0.001$ ), IL6 (HR, 2.7; $\mathrm{P}=1.4 \times 10^{-13}$ ), IL10 (HR, 2.8; $\left.\mathrm{P}=4.1 \times 10^{-13}\right)$ and $E R B B 2\left(\mathrm{HR}, 2.1 ; \mathrm{P}=1 \times 10^{-8}\right.$ ) was significantly associated with shorter OS time. By contrast, the high expression of NOTCHI (HR, 0.53; $\mathrm{P}=9 \times 10^{-7}$ ) and $S R C$ (HR, 0.62; $\mathrm{P}=0.00026)$ was associated with longer $\mathrm{OS}$ time in glioma (Fig. 4). 
Table IV. The enriched pathways of modules.

\begin{tabular}{|c|c|c|c|c|}
\hline Module & Term & P-value & FDR & Genes \\
\hline 1 & hsa05152:Tuberculosis & $2.06 \times 10^{-12}$ & $2.45 \times 10^{-9}$ & $\begin{array}{l}\text { AKT1,TNFRSF 1A, CASP3,IL6,TNF, BAX, CREB1, CASP8,IFNG, } \\
\text { IL1B, JAK2, NOS2, IL10 }\end{array}$ \\
\hline 1 & hsa05145:Toxoplasmosis & $1.12 \times 10^{-11}$ & $1.33 \times 10^{-8}$ & $\begin{array}{l}\text { AKT1, TNFRSF1A, CASP3, TNF, CCR5, CASP8, IFNG, JAK2, } \\
\text { CD40,NOS2,IL10 }\end{array}$ \\
\hline 1 & $\begin{array}{l}\text { hsa05142:Chagas disease } \\
\text { (American trypanosomiasis) }\end{array}$ & $2.27 \times 10^{-10}$ & $2.69 \times 10^{-7}$ & $\begin{array}{l}\text { AKT1, TNFRSF1A, IL6, CCL3, TNF, CASP8, IFNG, IL1B, NOS2, } \\
\text { IL10 }\end{array}$ \\
\hline 1 & $\begin{array}{l}\text { hsa04060:Cytokine- } \\
\text { cytokine receptor } \\
\text { interaction }\end{array}$ & $1.68 \times 10^{-9}$ & $2.00 \times 10^{-6}$ & $\begin{array}{l}\text { TNFRSF1A, IL6, TNFSF10, CCL3, TNF , CCR5, IFNG, IL1B, IL13, } \\
\text { CD40,IL10,IL11 }\end{array}$ \\
\hline 1 & hsa05161:Hepatitis B & $4.48 \times 10^{-9}$ & $5.33 \times 10^{-6}$ & $\begin{array}{l}\text { AKT1, CASP3, IL6, TNF, KRAS, BAX, CREB1, MMP9, CASP8, } \\
\text { PTEN }\end{array}$ \\
\hline 2 & $\begin{array}{l}\text { hsa04060:Cytokine- } \\
\text { cytokine receptor } \\
\text { interaction }\end{array}$ & $1.44 \times 10^{-4}$ & $1.57 \times 10^{-1}$ & OSM, LIF, TNFRSF 10A, CSF3, FAS, IL12B, IL1A \\
\hline 2 & $\begin{array}{l}\text { hsa05205:Proteoglycans in } \\
\text { cancer }\end{array}$ & $5.35 \times 10^{-4}$ & $5.82 \times 10^{-1}$ & $I G F 1 R, F A S, I L 12 B, M M P 2, I T G B 1, P L A U$ \\
\hline 2 & hsa05162:Measles & $1.05 \times 10^{-3}$ & 1.14 & TNFRSF10A, STAT5A, FAS, IL12B, IL1A \\
\hline 2 & $\begin{array}{l}\text { hsa04630:Jak-STAT } \\
\text { signaling pathway }\end{array}$ & $1.45 \times 10^{-3}$ & 1.57 & OSM , LIF, CSF3, STAT5A, IL12B \\
\hline 2 & $\begin{array}{l}\text { hsa05202: Transcriptional } \\
\text { misregulation in cancer }\end{array}$ & $2.44 \times 10^{-3}$ & 2.62 & $I G F 1 R, S P I 1, M P O, M M P 3, P L A U$ \\
\hline 3 & $\begin{array}{l}\text { hsa05217:Basal cell } \\
\text { carcinoma }\end{array}$ & $1.82 \times 10^{-6}$ & $1.29 \times 10^{-3}$ & WNT5A, SMO, PTCH1, GLI2 \\
\hline 3 & $\begin{array}{l}\text { hsa05200:Pathways in } \\
\text { cancer }\end{array}$ & $1.05 \times 10^{-5}$ & $7.46 \times 10^{-3}$ & WNT5A, SMO, FGF9, PTCH1, GLI2 \\
\hline 3 & $\begin{array}{l}\text { hsa04340:Hedgehog } \\
\text { signaling pathway }\end{array}$ & $8.86 \times 10^{-5}$ & $6.29 \times 10^{-2}$ & SMO, PTCH1, GLI2 \\
\hline 3 & $\begin{array}{l}\text { hsa05205:Proteoglycans } \\
\text { in cancer }\end{array}$ & $4.86 \times 10^{-3}$ & 3.40 & WNT5A, SMO, PTCH1 \\
\hline 3 & $\begin{array}{l}\text { hsa04390:Hippo } \\
\text { signaling pathway }\end{array}$ & $8.50 \times 10^{-2} 4$ & 46.77 & WNT5A, GLI2 \\
\hline 4 & hsa05310:Asthma & $7.49 \times 10^{-8}$ & $5.78 \times 10^{-5}$ & $H L A-D P A 1, H L A-D P B 1, H L A-D Q A 2, H L A-D O B$ \\
\hline 4 & $\begin{array}{l}\text { hsa05332:Graft-vs. } \\
\text {-host disease }\end{array}$ & $1.01 \times 10^{-7}$ & $7.77 \times 10^{-5}$ & HLA-DPA1, HLA-DPB1, HLA-DQA2, HLA-DOB \\
\hline 4 & $\begin{array}{l}\text { hsa05330:Allograft } \\
\text { rejection }\end{array}$ & $1.43 \times 10^{-7}$ & $1.11 \times 10^{-4}$ & $H L A-D P A 1, H L A-D P B 1, H L A-D Q A 2, H L A-D O B$ \\
\hline 4 & $\begin{array}{l}\text { hsa04940:Type I } \\
\text { diabetes mellitus }\end{array}$ & $2.12 \times 10^{-7}$ & $1.63 \times 10^{-4}$ & $H L A-D P A 1, H L A-D P B 1, H L A-D Q A 2, H L A-D O B$ \\
\hline 4 & $\begin{array}{l}\text { hsa04672:Intestinal } \\
\text { immune network for } \\
\text { IgA production }\end{array}$ & $2.99 \times 10^{-7}$ & $2.31 \times 10^{-4}$ & $H L A-D P A 1, H L A-D P B 1, H L A-D Q A 2, H L A-D O B$ \\
\hline
\end{tabular}

FDR, false discovery rate; hsa, Homo sapiens.

\section{Discussion}

Glioma is the most common malignant tumor of the CNS (26). Despite drastic treatment, including neurosurgical resection after which radiotherapy in combination with temozolomide is used, a poor prognosis and high recurrence rate remains (27). Genetic and epigenetic alterations play a vital role in cellular transformation and therapy resistance (28). Therefore, potential specific molecular biomarkers and core therapeutic targets require further investigation. Global genomic hypomethylation and promoter hypermethylation of key genes is a hallmark of various types of cancer, such as lymphoma, breast and ovarian cancer (29). DNA methylation can alter the expression level of genes, which can further influence the proliferation and 
A
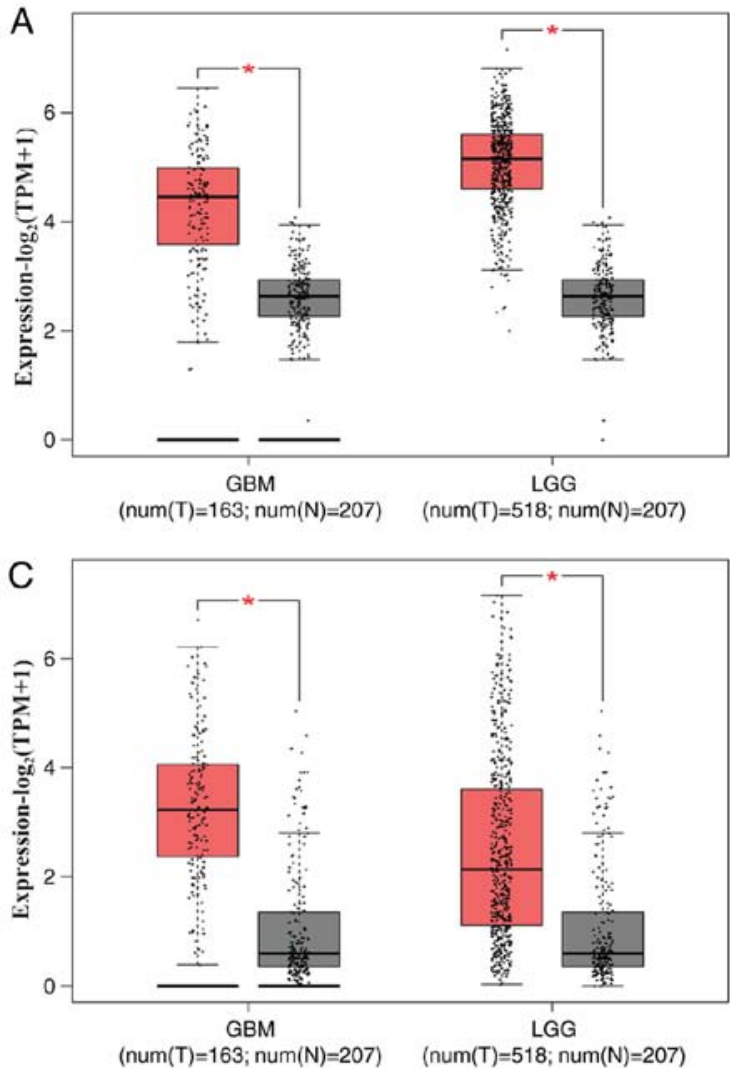

$\mathrm{E}$
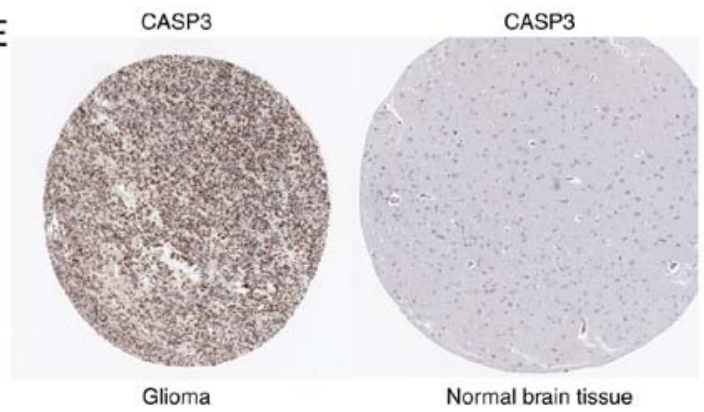
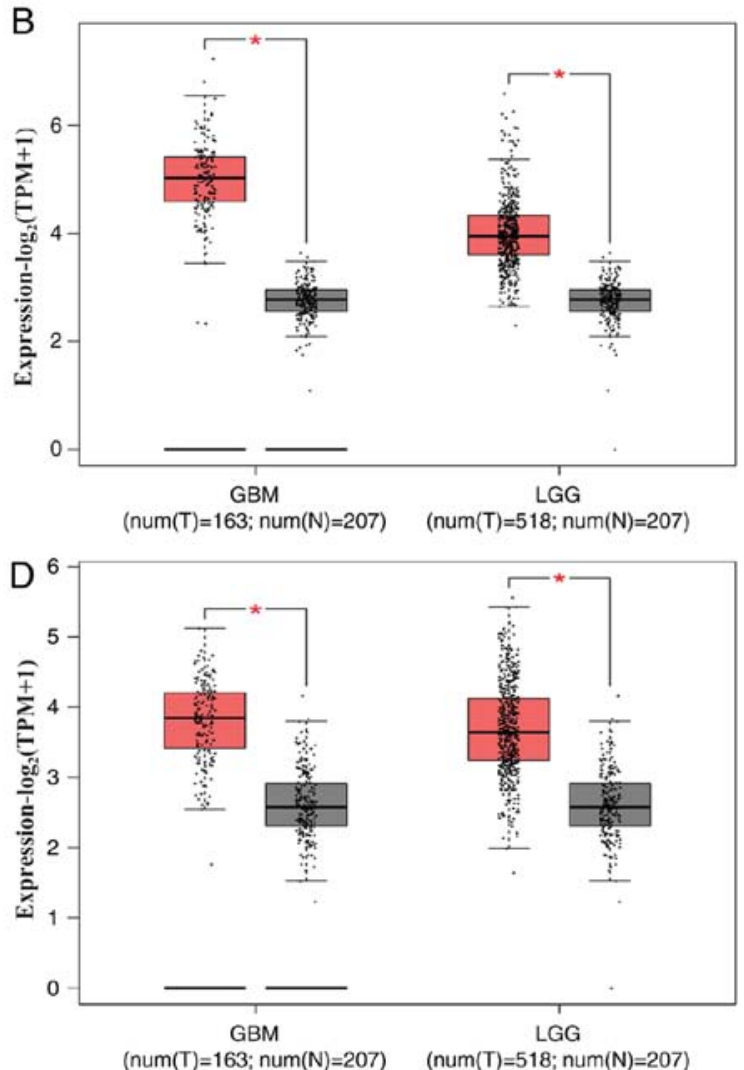

$\mathrm{F}$
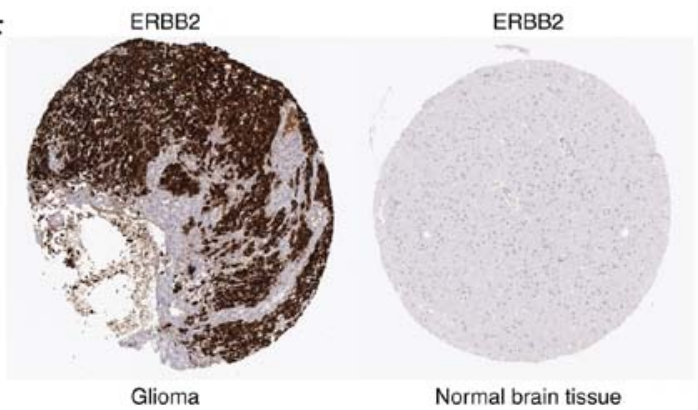

Figure 3. Expression level of the hub genes in glioma and normal brain tissues. (A-D) Expression level of (A) NOTCH1, (B) CASP3, (C) IL1B and (D) CREB1 in glioma and normal brain tissues. Red indicates glioma, gray indicates normal brain tissue. (E) CASP3 protein was strongly upregulated in glioma tissues compared with normal brain tissues based on the Human Protein Atlas database. (F) ERBB2 protein was strongly upregulated in glioma tissues compared with normal brain tissues based on the Human Protein Atlas database. ${ }^{*} \mathrm{P}<0.05$. GBM, glioblastoma multiforme; LGG, brain lower grade glioma; TPM, transcripts per million. $N O T C H 1$, notch receptor $1 ; C A S P 3$, caspase 3; IL1B, interleukin $1 \beta ; C R E B 1$, cAMP responsive element binding protein 1; ERBB2, erb-b2 receptor tyrosine kinase 2 .

migration of tumor cells (30). Hypomethylation has been verified to result in chromosome instability by activating the transcription of the commonly silenced transposons, similar to repetitive sequences (31). Aberrant gene promoter region hypermethylation of certain tumor suppressor genes, such as $M L H 1, M G M T$, and $C D K N 2 A$ genes, can lead to epigenetic silencing of such gene expression, which is associated with vital biological processes, including DNA repair and cell cycle control (32). Therefore, in order to gain a further understanding of the underlying mechanisms that affect the incidence and development of glioma, epigenetic alterations require further investigation. Bioinformatics analysis provides objective data for this purpose. In the present study, the GSE28094 dataset, containing 90 gliomas and 6 normal brain tissues, was extracted from GEO as a discovery set. Numerous bioinformatics tools detected a total of 349 DMGs, including 167 hypermethylated genes and 182 hypomethylated genes, which may be associated with the tumorigenicity and progression of glioma.

As revealed by GO analysis, hypomethylated genes in glioma were enriched in BPs of 'immune response', 'cellular response to lipopolysaccharide', 'peptidyl-tyrosine phosphorylation', 'inflammatory response' and 'extracellular matrix (ECM) disassembly'. MF indicated enrichment in 'cytokine activity', 'protein tyrosine kinase activity', 'growth factor activity', 'phosphatidylinositol-4,5-bisphosphate 3-kinase activity' and 'non-membrane spanning protein tyrosine kinase activity'. In addition, for hypermethylated genes in glioma, GO analysis indicated that enriched BPs were positive and negative regulation of 'cell proliferation', 'positive regulation of transcription from RNA polymerase II promoter', 'protein autophosphorylation' and 'regulation of apoptotic process'. MF enrichment revealed 'protein binding', 'transcription factor binding', 'protein heterodimerization activity', 'receptor binding' and 'ATP binding'. These 
Table V. Top 20 hub genes with the highest degree of connectivity, and validation of the hub genes in The Cancer Genome Atlas database.

\begin{tabular}{|c|c|c|c|c|c|}
\hline Gene & Degree of connectivity & Methylation status & Adjusted P-value & P-value & Expression status \\
\hline$A K T 1$ & 121 & Hypermethylation & $1.09 \times 10^{-5}$ & $4.71 \times 10^{-7}$ & Upregulation \\
\hline$S R C$ & 112 & Hypomethylation & $2.08 \times 10^{-3}$ & $2.27 \times 10^{-4}$ & No change \\
\hline$E G F$ & 112 & Hypomethylation & $1.35 \times 10^{-2}$ & $2.54 \times 10^{-3}$ & No change \\
\hline$T N F$ & 110 & Hypomethylation & $4.62 \times 10^{-2}$ & $1.43 \times 10^{-2}$ & No change \\
\hline IL6 & 108 & Hypomethylation & $4.76 \times 10^{-2}$ & $1.47 \times 10^{-2}$ & Upregulation \\
\hline NOTCHI & 88 & Hypomethylation & $5.76 \times 10^{-13}$ & $4.59 \times 10^{-15}$ & Upregulation \\
\hline ILS & 81 & Hypomethylation & $1.30 \times 10^{-3}$ & $1.26 \times 10^{-4}$ & No change \\
\hline$M M P 9$ & 77 & Hypomethylation & $2.64 \times 10^{-2}$ & $6.41 \times 10^{-3}$ & Upregulation \\
\hline ILIO & 76 & Hypomethylation & $4.29 \times 10^{-2}$ & $1.31 \times 10^{-2}$ & Upregulation \\
\hline CASP3 & 75 & Hypermethylation & $2.70 \times 10^{-2}$ & $6.66 \times 10^{-3}$ & Upregulation \\
\hline$I L I B$ & 74 & Hypomethylation & $1.43 \times 10^{-2}$ & $2.78 \times 10^{-3}$ & Upregulation \\
\hline$C S F 2$ & 73 & Hypomethylation & $3.50 \times 10^{-2}$ & $9.68 \times 10^{-3}$ & No change \\
\hline PTEN & 72 & Hypermethylation & $1.90 \times 10^{-2}$ & $4.13 \times 10^{-3}$ & No change \\
\hline$E R B B 2$ & 70 & Hypermethylation & $1.18 \times 10^{-2}$ & $2.10 \times 10^{-3}$ & Upregulation \\
\hline$C D K N 2 A$ & 67 & Hypermethylation & $3.58 \times 10^{-2}$ & $1.00 \times 10^{-2}$ & Upregulation \\
\hline$C D 34$ & 66 & Hypermethylation & $8.65 \times 10^{-4}$ & $7.93 \times 10^{-5}$ & No change \\
\hline$J A K 2$ & 63 & Hypermethylation & $2.23 \times 10^{-5}$ & $1.05 \times 10^{-6}$ & No change \\
\hline$I F N G$ & 63 & Hypomethylation & $3.77 \times 10^{-2}$ & $1.07 \times 10^{-2}$ & No change \\
\hline$K R A S$ & 59 & Hypermethylation & $9.14 \times 10^{-3}$ & $1.49 \times 10^{-3}$ & No change \\
\hline CREB1 & 58 & Hypomethylation & $1.53 \times 10^{-5}$ & $7.03 \times 10^{-7}$ & Upregulation \\
\hline
\end{tabular}

results suggested that dysregulation of cell proliferation and apoptosis may serve an important role in the occurrence and development of tumors, which was in agreement with previous studies $(33,34)$. As a major component of tumor local microenvironment, the ECM affects tumor progression by promoting cell transformation and metastasis (35). Notably, ECM anomalies also lead to stromal cell deregulation and facilitate tumor-associated angiogenesis and inflammation, which comprise the tumorigenic microenvironment (35). It has been reported that active but dysfunctional immune responses are associated with cancer (36). Clinical data have indicated that immune stimulation and immune suppression simultaneously occur in patients with cancer, with increased concentrations of $\mathrm{TNF} \alpha$, interleukin (IL)6, IL8 and IL10 (37), which is in accordance with the results of the present study. Therefore, tumor-promoting immune disorder may serve a pivotal role in glioma oncogenesis, suggesting that cancer immunotherapy is likely to become a key part of the clinical management of glioma.

KEGG analysis revealed that DMGs were significantly enriched in pathways including 'cancer', 'signaling pathways regulating pluripotency of stem cells', 'PI3K-AKT signaling pathway', 'focal adhesion' and 'melanoma'. Activated $A K T$ modulates the function of numerous substrates, such as $m T O R$, glycogen synthase kinase $3 \beta$ or forkhead box protein $\mathrm{O} 1$, which are involved in the regulation of cell metabolism, proliferation, cell cycle progression and survival (38). In recent years, the PI3K/AKT signaling pathway has been associated with tumorigenesis and development of GBM (39). Pluripotent mouse embryonic stem cells can be expanded in large numbers in vitro by symmetrical self-renewal (40). Self-renewal entails proliferation with a concomitant suppression of differentiation, which is responsible for the occurrence and progression of cancer (40). Furthermore, differentially methylated regions in induced pluripotent stem cells, derived by epigenetic reprogramming, are significantly enriched in specific tissues and cancer, demonstrating that hypermethylation and hypomethylation of cytosine-phosphate-guanine islands are broadly involved in tissue differentiation, epigenetic reprogramming and cancer (41).

In addition, focal adhesion is associated with tumor cell migration and invasion (42). A previous study have shown that the expression and activity of focal adhesion kinase, an intracellular non-receptor tyrosine kinase, is frequently associated with cell adhesion, migration, survival, proliferation, differentiation and angiogenesis in cancer (43). These findings demonstrated the reliability of the present results, indicating the critical role of the PI3K/AKT signaling pathway, pluripotency of stem cells and focal adhesion kinase in the tumorigenicity of glioma, providing a promising therapeutic target for glioma.

The PPI network for DMGs uncovered the overview of their functional connections. The top 20 hub genes were also selected, in which five DMGs with a high degree of connectivity were identified: AKT1, SRC, EGF, TNF and IL6 (gene count $>100)$. Furthermore, TCGA database analysis was used to validate the top 20 hub genes. The results revealed that the hypomethylation of IL6, NOTCHI, MMP9, ILIO, ILIB and $C R E B 1$ was associated with high expression levels in glioma. Moreover, immunochemistry images of these hub genes were obtained from HPA. Compared with that of the other eight hub genes (AKT1,IL6, NOTCH1, MMP9, IL10,IL1B, CDKN2A and $C R E B 1)$, the expression intensity and quantity of $C A S P 3$ and $E R B B 2$ were higher in glioma. Therefore, the immunochemistry images of $C A S P 3$ and $E R B B 2$ were selected to visualize their 

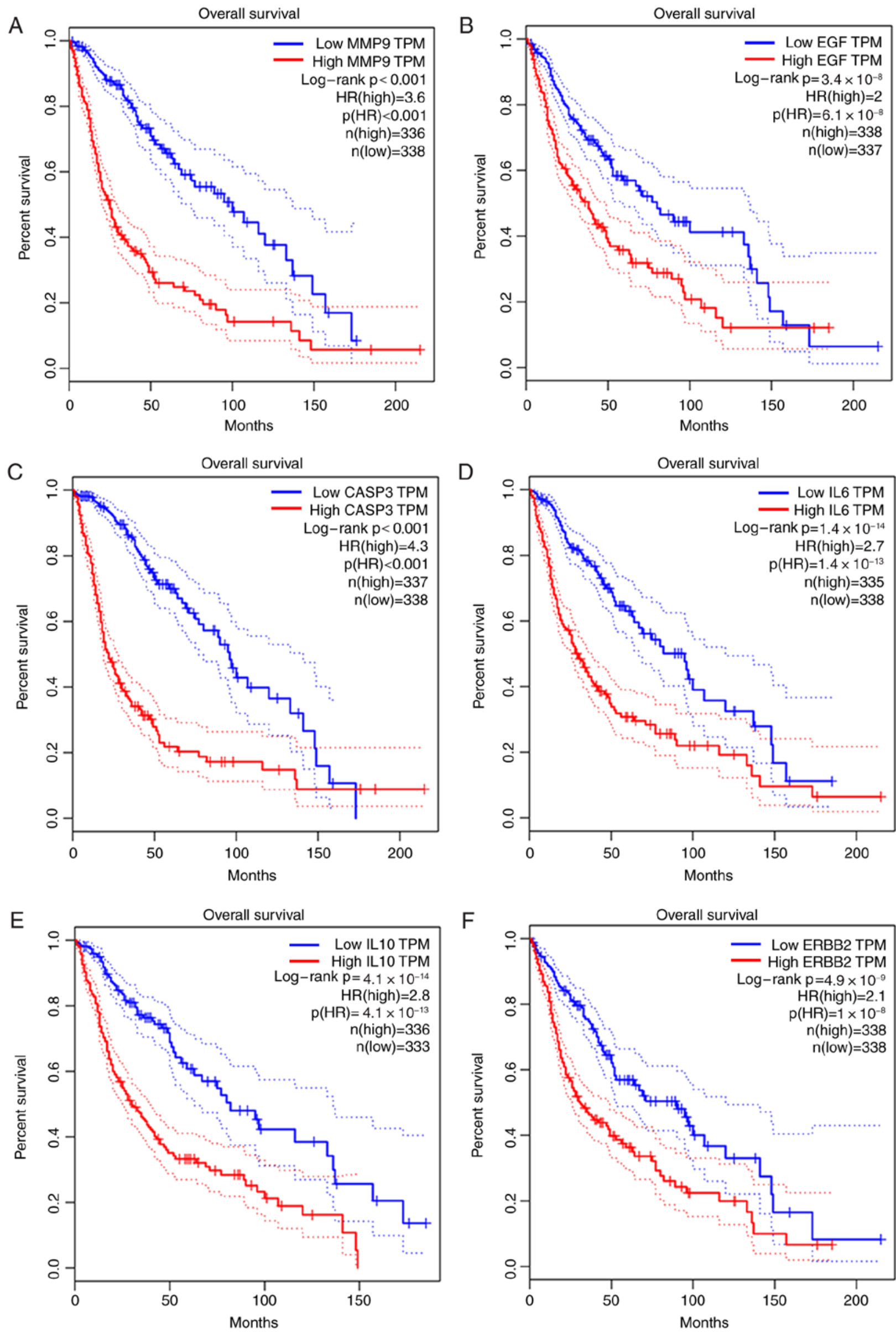

Figure 4. Prognostic value of eight differentially methylated genes in patients with glioma. (A-F) High expression of (A) $M M P 9$, (B) $E G F$, (C) $C A S P 3$, (D) $I L 6$, (E) IL10 and (F) ERBB2 was significantly associated with poor prognosis in glioma patients. 

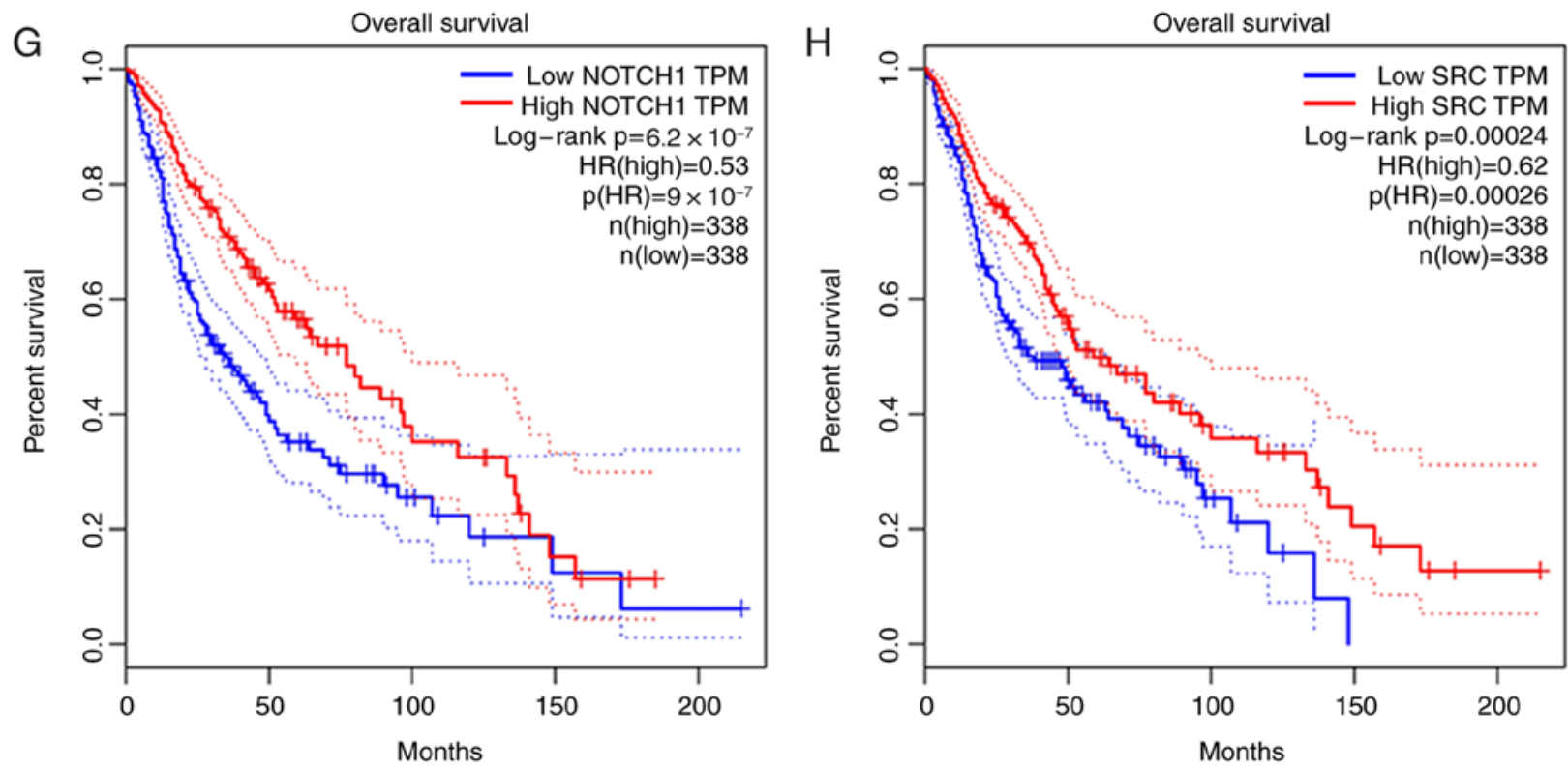

Figure 4. Continued. (G and H) High expression of (G) NOTCH1 and (H) SRC was associated with improved prognosis in glioma patients. HR, hazard ratio; TPM, Transcripts per million; $M M P 9$, matrix metallopeptidase 9; EGF, epidermal growth factor; CASP3, caspase 3; IL6, interleukin 6; IL10, interleukin 10; $E R B B 2$, erb-b2 receptor tyrosine kinase 2; $N O T C H 1$, notch receptor 1; SRC, SRC proto-oncogene.

differential expression level in glioma vs. normal brain tissue. It was revealed that eight genes were associated with survival, which were either protective or risky, based on HR. NOTCHI and $S R C$ were defined as protective with $\mathrm{HR}<1$, whereas IL6, $M M P 9, I L 10, C A S P 3, E R B B 2$ and EGF were defined as risky with $H R>1$. The aforementioned genes identified in the present study may serve as valuable prognostic biomarkers in glioma.

In previous studies, a number of these hub genes have already been examined as promising predictors of glioma. For instance, ILs, including IL6 and IL10, two important Th2-associated cytokines, are often co-expressed in glioma and further participate in malignancy progression and lead to an unfavorable prognosis $(44,45)$. MMP9 contributes to the degradation of ECM, angiogenesis and the invasiveness of glioma (46). AKT1 kinase is a crucial member of activated proliferation and survival pathways in cancer, which has the ability to suppress apoptosis, deregulate the cell cycle and alter the angiogenic potential (47). Increased levels of AKT in $~ 80 \%$ of all GBM cases suggested that activation of the AKT pathway was strongly implicated in the development of GBM (48). Epidermal growth factor receptor (EGFR) is activated by binding of its extracellular ligand, EGF, resulting in enhanced cell proliferation, growth and survival (49). A series of signaling pathway cascades activated by EGF/EGFR are associated with GBM progression, including activation of K-RAS and AKT signaling and mammalian target of rapamycin, together with PI3K pathways (50). Accumulating evidence shows that NOTCH1 is upregulated in classical and proneural subtypes of GBM, and is associated with tumor grade (51). NOTCHI inhibition suppresses the biological behavior of metastasis, invasion and epithelial-mesenchymal transition (52). SRC is one of several oncogenic tyrosine kinases, which is activated in various types of cancer to influence survival and metastasis, such as lung cancer, breast cancer and melanoma (53). The SRC-linked STAT3/MMP pathway is responsible for glioma stem cell (GSC) maintenance and growth (54); therefore, the inhibition of the SRC/STAT3 pathway may be a novel therapeutic target in glioma. The $C R E B 1$ gene plays a crucial role in the development and progression in various types of cancer, such as colon cancer, ovarian cancer and bladder cancer (55). Overexpression of CREB1 is significantly associated with advanced WHO grade, Karnofsky Performance Scale and short survival time of patients with glioma (56). Furthermore, inhibition of CREBI activation can prevent GSC self-renewal and suppress neoplastic growth (57). The $E R B B 2$ proto-oncogene (also known as HER2) is one of the most useful molecules for classification and prognosis in cancer, and its activation and downstream signals are highly dependent on dimerization with EGFR (58). ERBB2, in combination with survivin and CD99 molecule, has the ability to form branched multipeptides, which stably bind with T2 cells to exhibit 40-60 and 60-80\% cytotoxic activity against the U251 GBM and primary cells, respectively; therefore, they are promising candidates for immunotherapeutic GBM treatment (59). Caspases are well-renowned proteases that play a central role in initiating and executing cell apoptosis (60). A number of human cancer cell lines, such as MCF7, HCC1500, CRL1500, MDA-MB-231, A549, DU145, HepG2, HeLa and HGC27, upregulate ERBB2 expression, which promotes tumor survival via inhibiting the apoptotic activity of $C A S P 3 / 8$ (61). Therefore, apoptosis-associated $C A S P 3$ is an important gene in human carcinogenesis. According to previous studies, the underlying mechanism of IFNG in glioma remains unclear, and further research is necessary (62).

In summary, through bioinformatics analysis of glioma microarray gene expression data, a total of 349 DMGs were obtained between glioma and normal brain tissue, including 167 hypermethylated and 182 hypomethylated genes. The results showed that $I L 6, M M P 9, I L 10, C A S P 3, E R B B 2$ and $E G F$, which were associated with the tumor immune 
microenvironment, may act in the progression of malignant glioma. Molecular biological experiments are further required to elucidate the function and mechanism of these identified candidate DMGs in glioma, thereby offering new implications on glioma immune microenvironment and immune-related therapy.

\section{Acknowledgements}

Not applicable.

\section{Funding}

The present study was supported by grants from the Resource Sharing Platform Construction of Science and Technology Department of the Autonomous Region (grant no. PT1802) and the Xinjiang Medical University Graduate Innovation Entrepreneurship Start-up Fund (grant no. CXCY2018018).

\section{Availability of data and materials}

The datasets used during the current study are available from the corresponding author on reasonable request.

\section{Authors' contributions}

All authors participated in the preparation of the manuscript. WZ conceived and designed the study. JX, HXG and WS conducted the research. YZ and QW standardized the procedure for sequence search. WLC, ML and MBW contributed to data analysis and revised the manuscript. JX wrote the first draft of the manuscript. All authors read and approved the final version of the manuscript.

\section{Ethics approval and consent to participate}

Not applicable.

\section{Patient consent for publication}

Not applicable.

\section{Competing interests}

The authors declare no competing interests.

\section{References}

1. Hu T and Xi J: Identification of COX5B as a novel biomarker in high-grade glioma patients. Onco Targets Ther 10: 5463-5470, 2017.

2. Song X, Zhang N, Han P, Moon BS, Lai RK, Wang K and Lu W: Circular RNA profile in gliomas revealed by identification tool UROBORUS. Nucleic Acids Res 44: e87, 2016.

3. Louis DN, Perry A, Reifenberger G, von Deimling A, Figarella-Branger D, Cavenee WK, Ohgaki H, Wiestler OD, Kleihues P and Ellison DW: The 2016 World Health Organization classification of tumors of the central nervous system: A summary. Acta Neuropathol 131: 803-820, 2016.

4. Komotar RJ, Otten ML, Gaetan M and Connolly ES Jr: Radiotherapy plus concomitant and adjuvant temozolomide for glioblastoma-a critical review. Clin Med Oncol 2: 421-422, 2008.

5. Sturm D, Pfister SM and Jones DTW: Pediatric gliomas: Current concepts on diagnosis, biology, and clinical management. J Clin Oncol 35: 2370-2377, 2017.
6. Duffau H: Paradoxes of evidence-based medicine in lower-grade glioma: To treat the tumor or the patient? Neurology 91: 657-662, 2018.

7. Demuth T and Berens ME: Molecular mechanisms of glioma cell migration and invasion. J Neurooncol 70: 217-228, 2004.

8. Yang AS, Estecio MR, Garcia-Manero G, Kantarjian HM and Issa JP: Comment on 'Chromosomal instability and tumors promoted by DNA hypomethylation' and 'Induction of tumors in nice by genomic hypomethylation'. Science 302: 1153, 2003.

9. Manel E: CpG island hypermethylation and tumor suppressor genes: A booming present, a brighter future. Oncogene 21: 5427-5440, 2002.

10. Feinberg AP and Vogelstein B: Hypomethylation of ras oncogenes in primary human cancers. Biochem Biophys Res Commun 111: 47-54, 1983.

11. Zhang L, Wang M, Wang W and Mo J: Incidence and prognostic value of multiple gene promoter methylations in gliomas. J Neurooncol 116: 349-356, 2014.

12. Esteller M, Garcia-Foncillas J, Andion E, Goodman SN, Hidalgo OF, Vanaclocha V, Baylin SB and Herman JG: Inactivation of the DNA-repair gene MGMT and the clinical response of gliomas to alkylating agents. N Engl J Med 343: 1350-1354, 2000

13. Li X, Pu J, Liu J, Chen Y, Li Y, Hou P, Shi B and Yang Q: The prognostic value of DAPK1 hypermethylation in gliomas: A site-specific analysis. Pathol Res Pract 214: 940-948, 2018.

14. Arifin MT, Hama S, Kajiwara Y, Sugiyama K, Saito T, Matsuura S, Yamasaki F, Arita K and Kurisu K: Cytoplasmic, but not nuclear, p16 expression may signal poor prognosis in high-grade astrocytomas. J Neurooncol 77: 273-277, 2006.

15. Watanabe T, Katayama Y, Yoshino A, Yachi K, Ohta T, Ogino A, Komine $\mathrm{C}$ and Fukushima T: Aberrant hypermethylation of p14ARF and O6-methylguanine-DNA methyltransferase genes in astrocytoma progression. Brain Pathol 17: 5-10, 2007.

16. Darnay BG, Besse A, Poblenz AT, Lamothe B and Jacoby JJ: TRAFs in RANK Signaling. Adv Exp Med Biol 597: 152-159, 2007.

17. Berdasco M, Ropero S, Setien F, Fraga MF, Lapunzina $P$, Losson R, Alaminos M, Cheung NK, Rahman N and Esteller M: Epigenetic inactivation of the Sotos overgrowth syndrome gene histone methyltransferase NSD1 in human neuroblastoma and glioma. Proc Natl Acad Sci USA 106: 21830-21835, 2009.

18. Pan Q, Shai O, Lee LJ, Frey BJ and Blencowe BJ: Deep surveying of alternative splicing complexity in the human transcriptome by high-throughput sequencing. Nat Genet 40: 1413-1415, 2008.

19. Fernandez AF, Assenov Y, Martin-Subero JI, Balint B, Siebert R, Taniguchi $\mathrm{H}$, Yamamoto $\mathrm{H}$, Hidalgo M, Tan AC, Galm O, et al: A DNA methylation fingerprint of 1628 human samples. Genome Res 22: 407-419, 2012.

20. Davis S and Meltzer PS: GEOquery: A bridge between the Gene Expression Omnibus (GEO) and BioConductor. Bioinformatics 23: 1846-1847, 2007.

21. Ashburner M, Ball CA, Blake JA, Botstein D, Butler H, Cherry JM, Davis AP, Dolinski K, Dwight SS, Eppig JT, et al: Gene ontology: Tool for the unification of biology. The Gene Ontology Consortium. Nat Genet 25: 25-29, 2000.

22. Kanehisa M and Goto S: KEGG: Kyoto Encyclopaedia of Genes and Genomes. Nucleic Acids Res 28: 27-30, 2000.

23. Ono K, Muetze T, Kolishovski G, Shannon P and Demchak B: CyREST: Turbocharging cytoscape access for external tools via a RESTful API. F1000Res 4: 478, 2015

24. Bader GD and Hogue CW: An automated method for finding molecular complexes in large protein interaction networks. BMC Bioinformatics 4: 2, 2003.

25. Tang Z, Li C, Kang B, Gao G, Li C and Zhang Z: GEPIA: A web server for cancer and normal gene expression profiling and interactive analyses. Nucleic Acids Res 45: W98-W102, 2017.

26. Ostrom QT, Gittleman H, Farah P, Ondracek A, Chen Y, Wolinsky Y, Stroup NE, Kruchko C and Barnholtz-Sloan JS: CBTRUS statistical report: Primary brain and central nervous system tumors diagnosed in the United States in 2006-2010. Neuro Oncol 15 (Suppl 2): ii1-ii56, 2013.

27. Alexander BM and Cloughesy TF: Adult Glioblastoma. J Clin Oncol 35: 2402-2409, 2017.

28. Bralten LB and French PJ: Genetic alterations in glioma. Cancers (Basel) 3: 1129-1140, 2011.

29. Gaudet F, Hodgson JG, Eden A, Jackson-Grusby L, Dausman J, Gray JW, Leonhardt H and Jaenisch R: Induction of tumors in mice by genomic hypomethylation. Science 300: 489-492, 2003.

30. Győrffy B, Bottai G, Fleischer T, Munkácsy G, Budczies J, Paladini L, Børresen-Dale AL, Kristensen VN and Santarpia L: Aberrant DNA methylation impacts gene expression and prognosis in breast cancer subtypes. Int J Cancer 38: 87-97, 2016. 
31. Dai D, Zhou B, Xu W, Jin H and Wang X: CHFR promoter hypermethylation is associated with gastric cancer and plays a protective role in gastric cancer process. J Cancer 10: 949-956, 2019.

32. Wang ZL, Zhang CB, Cai JQ, Li QB, Wang Z and Jiang T: Integrated analysis of genome-wide DNA methylation, gene expression and protein expression profiles in molecular subtypes of WHO II-IV gliomas. J Exp Clin Cancer Res 34: 127, 2015.

33. Johnstone RW, Ruefli AA and Lowe SW: Apoptosis: A link between cancer genetics and chemotherapy. Cell 108: 153-164, 2002.

34. Schlabach MR, Luo J, Solimini NL, Hu G, Xu Q, Li MZ, Zhao Z, Smogorzewska A, Sowa ME, Ang XL, et al: Cancer proliferation gene discovery through functional genomics. Science 319 620-624, 2008

35. Lu P, Weaver VM and Werb Z: The extracellular matrix: A dynamic niche in cancer progression. J Cell Biol 196: 395-406, 2012.

36. Chen DS and Mellman I: Oncology meets immunology: The cancer-immunity cycle. Immunity 39: 1-10, 2013.

37. Lippitz BE: Cytokine patterns in patients with cancer: A systematic review. Lancet Oncol 14: e218-e228, 2013.

38. Fresno Vara JA, Casado E, de Castro J, Cejas P, Belda-Iniesta C and González-Barón M: PI3K/Akt signalling pathway and cancer. Cancer Treat Rev 30: 193-204, 2004.

39. Majewska E and Szeliga M: AKT/GSK3 $\beta$ signaling in glioblastoma. Neurochem Res 42: 918-924, 2017.

40. Burdon T, Smith A and Savatier P: Signalling, cell cycle and pluripotency in embryonic stem cells. Trends Cell Biol 12: 432-438, 2002.

41. Doi A, Park IH, Wen B, Murakami P, Aryee MJ, Irizarry R Herb B, Ladd-Acosta C, Rho J, Loewer S, et al: Differential methylation of tissue- and cancer-specific $\mathrm{CpG}$ island shores distinguishes human induced pluripotent stem cells, embryonic stem cells and fibroblasts. Nat Genet 41: 1350-1353, 2009.

42. Sood AK, Coffin JE, Schneider GB, Fletcher MS, DeYoung BR, Gruman LM, Gershenson DM, Schaller MD and Hendrix MJ: Biological significance of focal adhesion kinase in ovarian cancer: Role in migration and invasion. Am J Pathol 165: 1087-1095, 2004.

43. Luo M and Guan JL: Focal adhesion kinase: A prominent determinant in breast cancer initiation, progression and metastasis. Cancer Lett 289: 127-139, 2010.

44. Cao F, Zhang Q, Chen W, Han C, He Y, Ran Q and Yao S: IL-6 increases SDCBP expression, cell proliferation, and cell invasion by activating JAK2/STAT3 in human glioma cells. Am J Transl Res 9: 4617-4626, 2017.

45. Samaras V, Piperi C, Korkolopoulou P, Zisakis A, Levidou G, Themistocleous MS, Boviatsis EI, Sakas DE, Lea RW, Kalofoutis A and Patsouris E: Application of the ELISPOT method for comparative analysis of interleukin (IL)-6 and IL-10 secretion in peripheral blood of patients with astroglial tumors. Mol Cell Biochem 304: 343-351, 2007.

46. Xue Q, Cao L, Chen XY, Zhao J, Gao L, Li SZ and Fei Z: High expression of MMP9 in glioma affects cell proliferation and is associated with patient survival rates. Oncol Lett 13: 1325-1330, 2017

47. Carpten JD, Faber AL, Horn C, Donoho GP, Briggs SL, Robbins CM, Hostetter G, Boguslawski S, Moses TY, Savage $\mathrm{S}$, et al: A transforming mutation in the pleckstrin homology domain of AKT1 in cancer. Nature 448: 439-444, 2007.

48. Holland EC, Celestino J, Dai C, Schaefer L, Sawaya RE and Fuller GN: Combined activation of Ras and Akt in neural progenitors induces glioblastoma formation in mice. Nat Genet 25: 55-57, 2000.

49. Kjær IM, Olsen DA, Alnor A, Brandslund I, Bechmann T and Madsen JS: EGFR and EGFR ligands in serum in healthy women; reference intervals and age dependency. Clin Chem Lab Med: Jul 16, 2019 doi: 10.1515/cclm-2019-0376 (Epub ahead of print).
50. Thorne $\mathrm{AH}$, Zanca $\mathrm{C}$ and Furnari F: Epidermal growth factor receptor targeting and challenges in glioblastoma. Neuro Oncol 18: 914-918, 2016.

51. Hai L, Zhang C, Li T, Zhou X, Liu B, Li S, Zhu M, Lin Y, Yu S, Zhang K, et al: Notch1 is a prognostic factor that is distinctly activated in the classical and proneural subtype of glioblastoma and that promotes glioma cell survival via the NF- $\mathrm{BB}(\mathrm{p} 65)$ pathway. Cell Death Dis 9: 158, 2018.

52. Sarkar S, Mirzaei R, Zemp FJ, Wei W, Senger DL, Robbins SM and Yong VW: Activation of NOTCH signaling by Tenascin-C promotes growth of human brain tumor-initiating cells. Cancer Res 77: 3231-3243, 2017.

53. Li MY, Peng WH, Wu CH, Chang YM, Lin YL, Chang GD, Wu HC and Chen GC: PTPN3 suppresses lung cancer cell invasiveness by counteracting Src-mediated DAAM1 activation and actin polymerization. Oncogene: Aug 12, 2019 doi: 10.1038/s41388-019-0948-6 (Epub ahead of print).

54. Guryanova OA, Wu Q, Cheng L, Lathia JD, Huang Z, Yang J, MacSwords J, Eyler CE, McLendon RE, Heddleston JM, et al: Nonreceptor tyrosine kinase BMX maintains self-renewal and tumorigenic potential of glioblastoma stem cells by activating STAT3. Cancer Cell 19: 498-511, 2011.

55. Tong L, Wang Y, Ao Y and Sun X: CREB1 induced lncRNA HAS2-AS1 promotes epithelial ovarian cancer proliferation and invasion via the miR-466/RUNX2 axis. Biomed Pharmacother 115: 108891, 2019.

56. Dong $\mathrm{H}, \mathrm{Cao} \mathrm{W}$ and Xue J: Long noncoding FOXD2-AS1 is activated by CREB1 and promotes cell proliferation and metastasis in glioma by sponging miR-185 through targeting AKT1. Biochem Biophys Res Commun 508: 1074-1081, 2019.

57. Mukherjee S, Tucker-Burden C, Kaissi E, Newsam A, Duggireddy $\mathrm{H}$, Chau M, Zhang C, Diwedi B, Rupji M, Seby S, et al: CDK5 Inhibition resolves PKA/cAMP-independent activation of CREB1 signaling in glioma stem cells. Cell Rep 23: 1651-1664, 2018.

58. Brennan PJ, Kumagai T, Berezov A, Murali R and Greene MI: HER 2/Neu: Mechanisms of dimerization/oligomerization. Oncogene 19: 6093-6101, 2000.

59. Kim YH, Tran TA, Lee HJ, Jung SI, Lee JJ, Jang WY, Moon KS, Kim IY, Jung S and Jung TY: Branched multipeptide immunotherapy for glioblastoma using human leukocyte antigen- $A^{*} 0201-$ restricted cytotoxic T-lymphocyte epitopes from ERBB2, BIRC5 and CD99. Oncotarget 7: 50535-50547, 2016.

60. Bagnjuk K, Kast VJ, Tiefenbacher A, Kaseder M, Yanase T, Burges A, Kunz L, Mayr D and Mayerhofer A: Inhibitor of apoptosis proteins are potential targets for treatment of granulosa cell tumors-implications from studies in KGN. J Ovarian Res 12: 76, 2019.

61. Arman K, Ergün S, Temiz E and Öztuzcu S: The interrelationship between HER 2 and CASP3/8 with apoptosis in different cancer cell lines. Mol Biol Rep 41: 8031-8036, 2014.

62. Michaelsen SR, Urup T, Olsen LR, Broholm H, Lassen U and Poulsen HS: Molecular profiling of short-term and long-term surviving patients identifies CD34 mRNA level as prognostic for glioblastoma survival. J Neurooncol 137: 533-542, 2018.

This work is licensed under a Creative Commons Attribution-NonCommercial-NoDerivatives 4.0 International (CC BY-NC-ND 4.0) License. 